\begin{tabular}{lcccr} 
T H E & A R C H I V E & O F & M E C H A N I C A L & E N G I N E E R I N G \\
\hline VOL. LVII & 2010 & Number 3
\end{tabular}

10.2478/v10180-010-0016-9

Key words: microhydraulic, cavitation, noise

\author{
WACEAW KOLLEK * ZYGMUNT KUDŹMA ** JANUSZ RUTAŃSKI *** MICHAE \\ STOSIAK ${ }^{* * * *}$
}

\title{
ACOUSTIC PROBLEMS RELATING TO MICROHYDRAULIC COMPONENTS AND SYSTEMS
}

\begin{abstract}
This paper presents selected applications of the miniaturized hydraulic components offered by specialized manufacturers and some results of the authors' own research on microflows, including results of hydraulic microfeeder vibration measurements performed by the touchless method using a laser vibrometer. The latter was chosen in order to eliminate measuring instrument influence on the investigated microhydraulic object. Special attention was focused on acoustic problems: noise sources and methods of noise reduction.
\end{abstract}

\section{Introduction}

At the turn of the 19th and 20th century, the development and application of hydraulic drives and (microhydraulic) components have greatly accelerated. Hydraulic drives have supplanted conventional power or electric drives in many fields. Thanks to the intensive development of mechatronics (including hydrotronics) and microhydraulics, the hydraulic drive becomes even more competitive. This is so also because hydrotronic and microhydraulic sys-

* Wrocław University of Technology, Institute of Machines Design and Operation, Department of Hydraulic Drives and Automatics, ul. Eukasiewicza 7/9, 50-371 Wroctaw, Poland; E-mail: waclaw.kollek@pwr.wroc.pl

** Wrocław University of Technology, Institute of Machines Design and Operation, Department of Hydraulic Drives and Automatics, ul. Eukasiewicza 7/9, 50-371 Wroctaw, Poland; E-mail: zygmunt.kudzma@pwr.wroc.pl

*** Wrocław University of Technology, Institute of Machines Design and Operation, Department of Hydraulic Drives and Automatics, ul. Eukasiewicza 7/9, 50-371 Wroctaw, Poland; E-mail: janusz.rutanski@pwr.wroc.pl

**** Wrocław University of Technology, Institute of Machines Design and Operation, Department of Hydraulic Drives and Automatics, ul. Eukasiewicza 7/9, 50-371 Wrocław, Poland; E-mail: michal.stosiak@pwr.wroc.pl 
tems can be easily automated, especially microprocessor controlled systems with proportional components [1]. Also the advanced integration of different fields of science observed in the case of hydrotronic and microhydraulic components favours the above trends. R\&D in this area focus on enhancing operating parameters to transfer greater power at the smallest losses and to meet the EU standards, in particular the ones concerning noise and vibration emission by modern hydraulic systems and their components. Flows, and so the application areas of microhydraulics, can be divided according to [1] as follows:

- very small flows $<2 \mathrm{~cm}^{3} / \mathrm{s}\left(<120 \mathrm{~cm}^{3} / \mathrm{min}\right)$

- small flows $2-50 \mathrm{~cm}^{3} / \mathrm{s}\left(120-3000 \mathrm{~cm}^{3} / \mathrm{min}\right)$

- medium flows $50-500 \mathrm{~cm}^{3} / \mathrm{s}\left(3-30 \mathrm{dm}^{3} / \mathrm{min}\right)$

- large flows $500-2000 \mathrm{~cm}^{3} / \mathrm{s}\left(30-120 \mathrm{dm}^{3} / \mathrm{min}\right)$

- very large flows $>2000 \mathrm{~cm}^{3} / \mathrm{s}\left(>120 \mathrm{dm}^{3} / \mathrm{min}\right)$

In the field of hydraulic drives, it is generally accepted that the group of microhydraulic components comprises components with a flow of up to $50 \mathrm{~cm}^{3} / \mathrm{s}$.

Microhydraulic systems and components are expected to:

- be reliable in their operation,

- emit little noise,

- have small dimensions, without any reduction in the power transferred.

Size reduction (down to between ten and twenty millimetres or a few centimetres) may result in lower material costs, but the manufacturing costs may significantly increase, e.g. because of the required high dimensional accuracy.

Microhydraulics is applied in cases where high power must be transferred and motion fluidity ensured under much reduced geometric dimensions. As a consequence of the advances made in microhydraulic components and systems, pneumatic and electromechanical systems are increasingly often supplanted by microhydraulic systems. Moreover, miniaturization allows microhydraulics to replace conventional hydraulics in all cases where, because of dimensions or mass, the latter cannot be applied. This occurs in food industry, chemical industry and medicine [2] where precise dosing of fluids at a flow rate of, e.g., $1 \mathrm{mdm}^{3} / 24 \mathrm{~h}, 10 \mathrm{mdm}^{3} / \mathrm{h}$ and $100 \mathrm{mdm}^{3} / \mathrm{h}$ under a pressure of $200-500 \mathrm{hPa}$ [3] is required. Microhydraulic systems are also used in the drives of operating tables, X-ray tables and dental chairs as well as in cases where mass reduction is desirable, i.e. in road rescue equipment, aviation, astronautics and the automotive industry.

Currently, there are worldwide companies specializing in the mass production of hydraulic microcomponents, whose clients are found in different branches of economy and industry. 


\section{Selected microhydraulic components}

As mentioned above, there are companies specializing in the production of hydraulic microcomponents such as pumps, valves, receivers and accessories (piping and accumulators). An example of a hydraulic microcomponent is the fixed-delivery axial multiplunger pump (Fig. 1) mass-produced by Hydro Leduc.
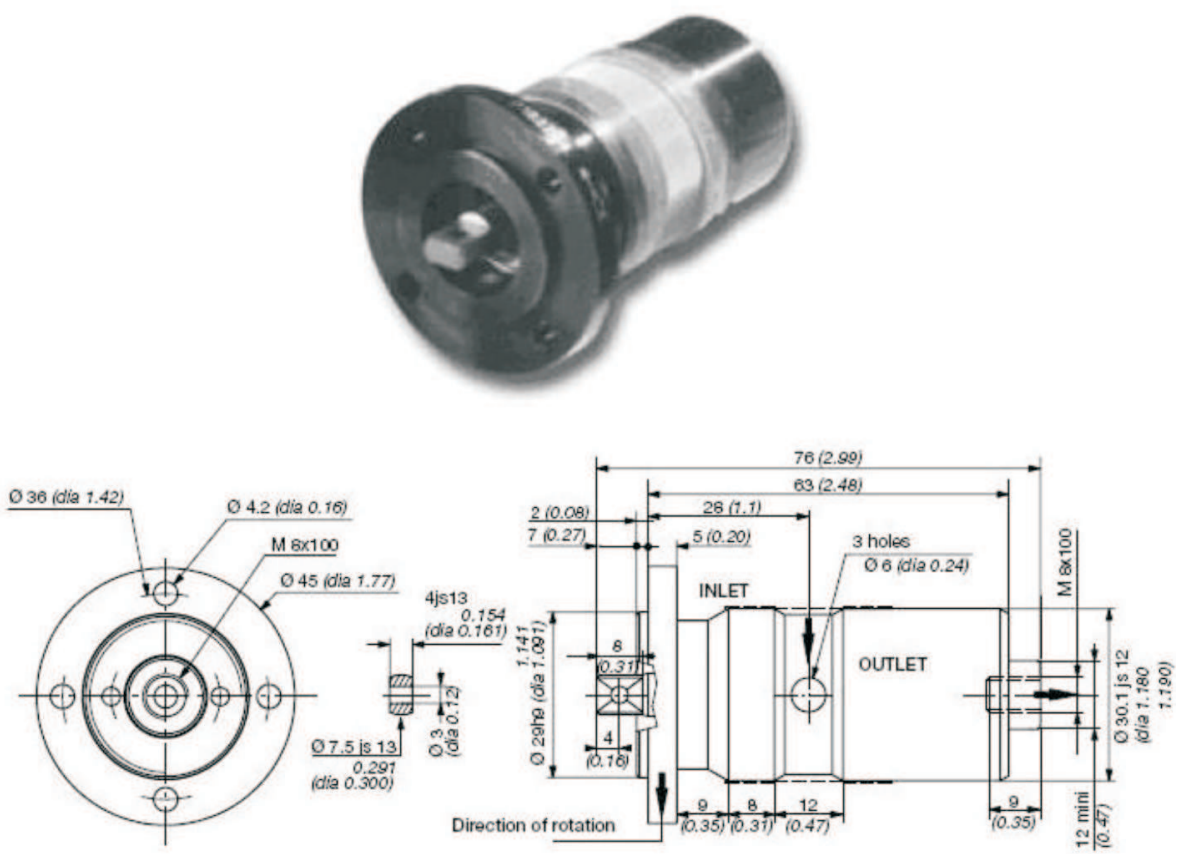

Fig. 1. Axial multiplunger micropump [4]. Dimensions in mm (inches)

The pump has three plungers. The manufacturer offers a whole range of such pumps with a specific delivery of $45-70 \mathrm{~mm}^{3} / \mathrm{rev}$., a rotational speed of up to $5000 \mathrm{rpm}$ and a maximum operating pressure of up to $100 \mathrm{MPa}$. The fact that the pump weighs merely $0.3 \mathrm{~kg}$ is worth noticing.

The Hoerbiger Microfluid company offers a wide range of hydraulic microcomponents. Figure 2 shows a microdistributor produced by this company [5].

The nominal flow in the microdistributor is $2 \mathrm{dm}^{3} / \mathrm{min}$. The working pressure is $25 \mathrm{MPa}$. The slide valve is held in the neutral position by springs and it reaches its maximum position owing to conventional $10 \mathrm{~W}$ electromagnets supplied with 12 or $24 \mathrm{~V}$. The weight of the distributor depends on its design, i.e. the number of slide valve conduits and positions, the type of elec- 


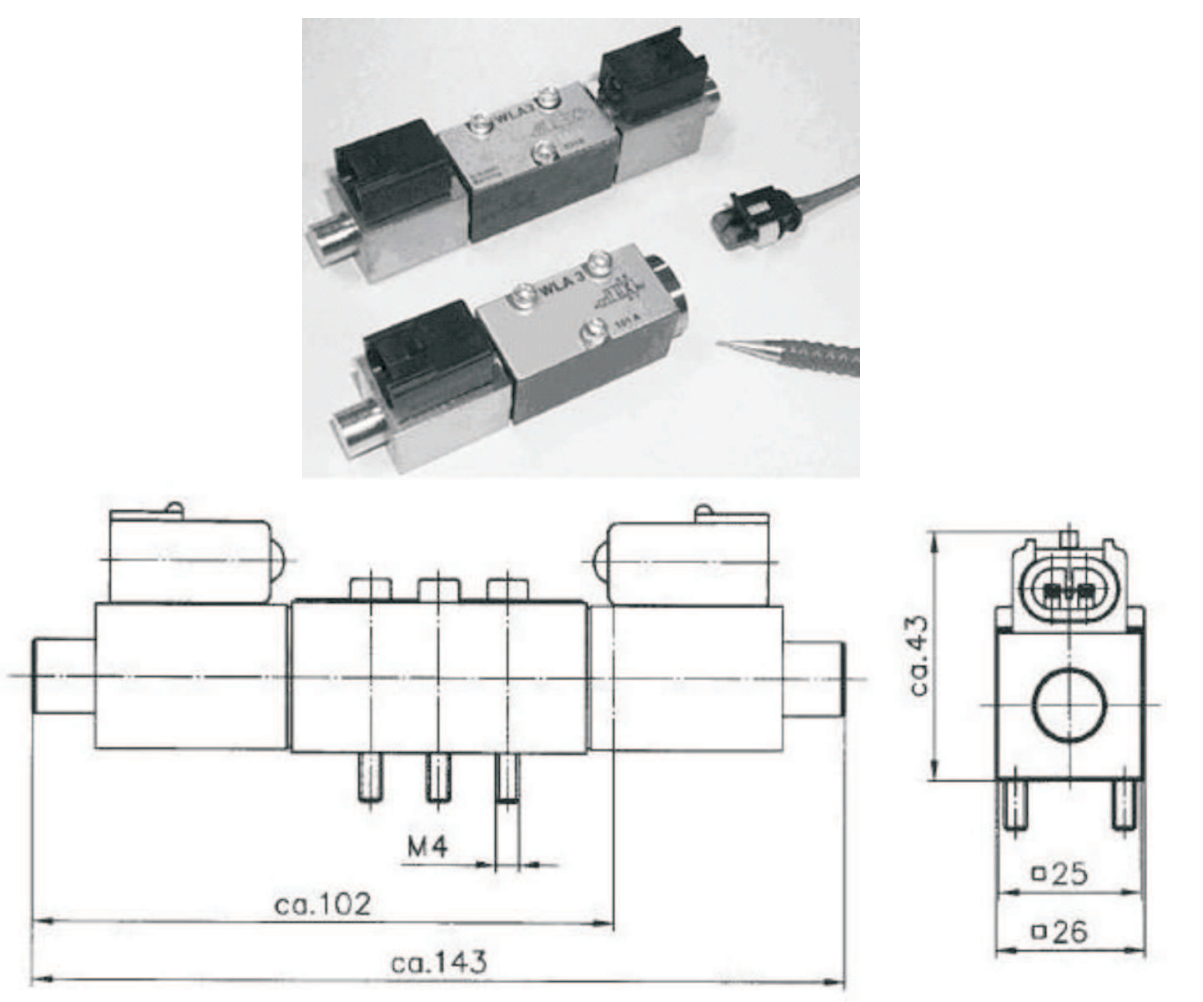

Fig. 2. Hydraulic microdistributor. Dimensions in mm, [5]

tromagnet (long or short electromagnets are offered), and so microdistributor $4 / 2$ weighs $410 \mathrm{~g}$ and the $4 / 3$ version weighs $560 \mathrm{~g}$.

Also hydraulic microcomponents with a $8-32 \mathrm{~mm}$ diameter plunger and a stroke of 120-1000 $\mathrm{mm}$ are commercially available. The maximum working pressure is $16 \mathrm{MPa}$. An example of such a hydraulic microactuator made by Hoerbiger Microfluid is shown in Fig. 3 [5].

The above examples of hydraulic components show that their weight and geometric dimensions have been minimized while maintaining relatively high working pressures. All the components are mass produced and belong to the main product range of numerous companies.

\section{Studies on hydraulic microfeeder}

Despite the existence of companies specializing in microhydraulics, research in this field, concerned with:

- cavitation,

- vibration and noise, 


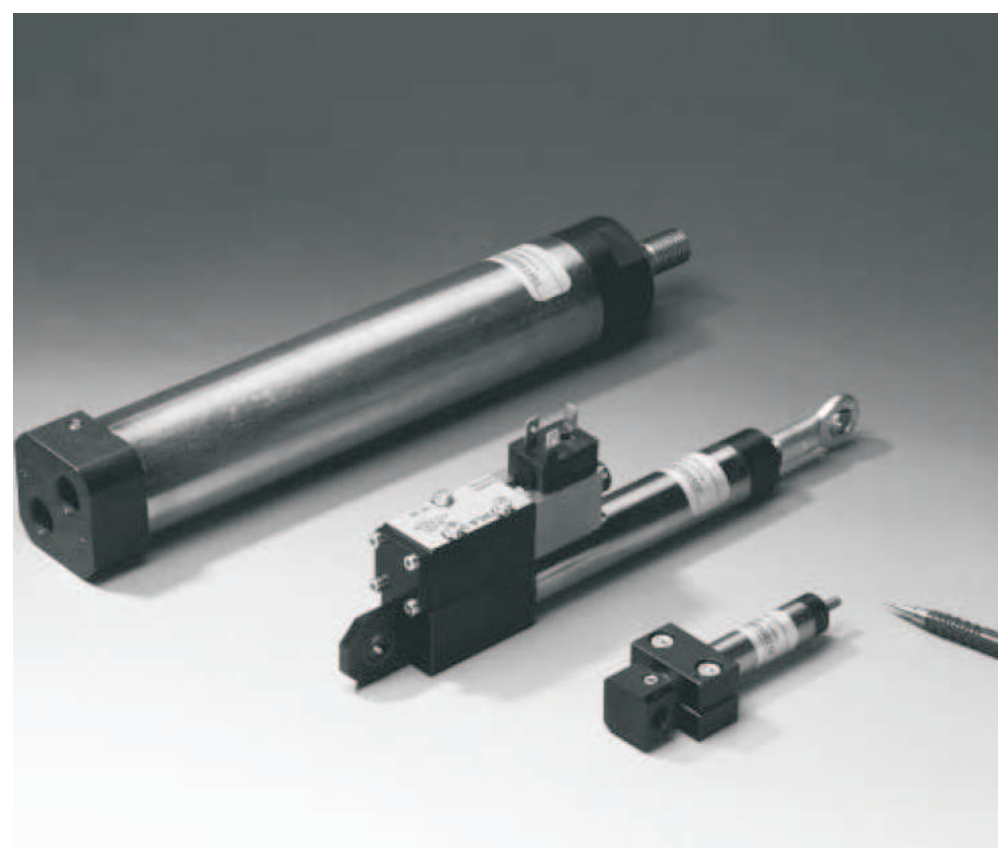

Fig. 3. Miniaturized hydraulic actuators [5]

- the occurrence of disturbing forces (which, especially in microhydraulics, can be as high as or higher than the control forces), etc.,

- is still needed.

Visualization studies on the flow of hydraulic oil through microhydraulic pipes were carried out in the Laboratory belonging to the Department of Hydraulic Drives and Automatics at Wrocław University of Technology. The development of cavitation is shown in Figs 4 and 5 [6].

Moreover, the authors studied cavitation in a $3 \mathrm{~mm} \phi$ diaphragm. Also the acoustic effect accompanying cavitation was studied. Figures $6 \mathrm{a}$ and $6 \mathrm{~b}$ show a diaphragm through which hydraulic oil HL 68 (with a temperature of $\left.20^{\circ} \mathrm{C}\right)$ flows. Flows without cavitation $\left(\mathrm{Q}=0.00033 \mathrm{~m}^{3} / \mathrm{s}, \mathrm{v}_{\text {diaph }}=46.7 \mathrm{~m} / \mathrm{s}\right.$, $\left.\Delta \mathrm{p}_{\text {diaph }}=1.6 \mathrm{MPa}\right)$ and with it $\left(\mathrm{Q}=0.00083 \mathrm{~m}^{3} / \mathrm{s}, \mathrm{v}_{\text {diaph }}=117.4 \mathrm{~m} / \mathrm{s}, \Delta \mathrm{p}_{\text {diaph }}\right.$ $=6.5 \mathrm{MPa}$ ) are shown in Fig. 6a and Fig. 6b, respectively.

Using an acoustic probe, we investigated the accompanying acoustic effect in the form of the spectrum of equivalent sound level $\mathrm{L}_{A}$. Figures $7 \mathrm{a}$ and $7 \mathrm{~b}$ show the spectrum for the flow without and with cavitation on the diaphragm.

An analysis of the results shows that $250 \mathrm{~Hz}$ (at which equivalent level $\mathrm{L}_{A} \approx 75 \mathrm{~dB}$ ) is the dominant frequency for the flow without cavitation, whereas for the flow with cavitation the dominant frequency is $10 \mathrm{kHz}$ (at which equivalent level $\mathrm{L}_{A}$ is over $100 \mathrm{~dB}$ ). In the low and medium frequency 


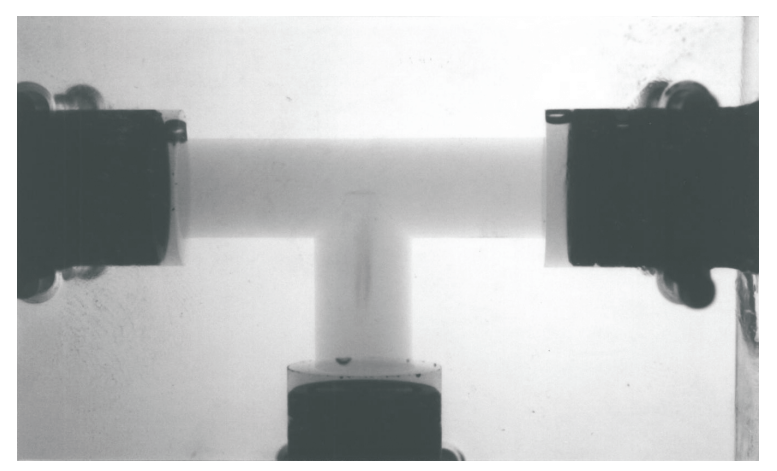

Fig. 4. Beginning of cavitation in pipe with inside diameter of $0.8 \cdot 10^{-3} \mathrm{~m}, \mathrm{Q}=1.75 \times 10^{3}$ $\mathrm{cm}^{3} / \mathrm{min}, \Delta \mathrm{p}=3.7 \mathrm{MPa}$

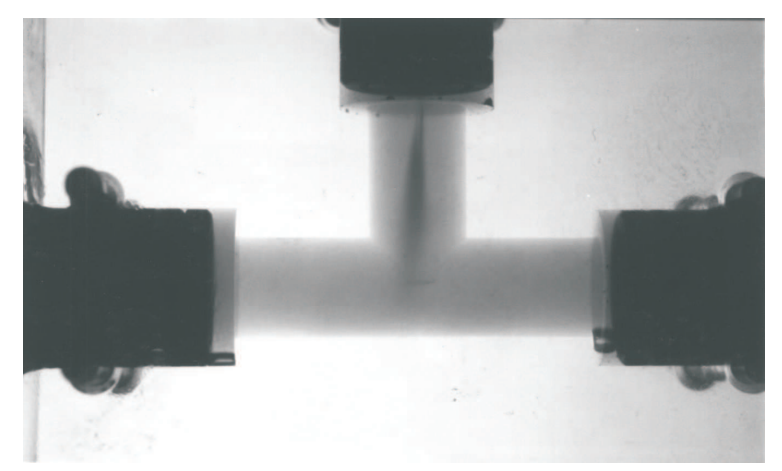

Fig. 5. Cavitation of pipe with inside diameter of $0.8 \cdot 10^{-3} \mathrm{~m}, \mathrm{Q}=3.5 \times 10^{3} \mathrm{~cm}^{3} / \mathrm{min}, \Delta \mathrm{p}=3.7$ $\mathrm{MPa}$

a)

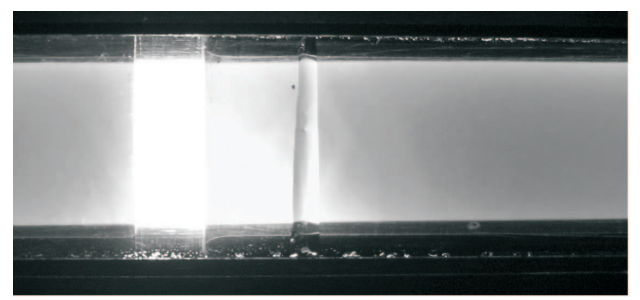

b)

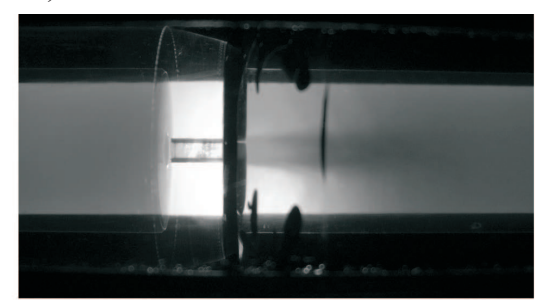

Fig. 6. a) Flow without cavitation; b) Flow with cavitation 
a)

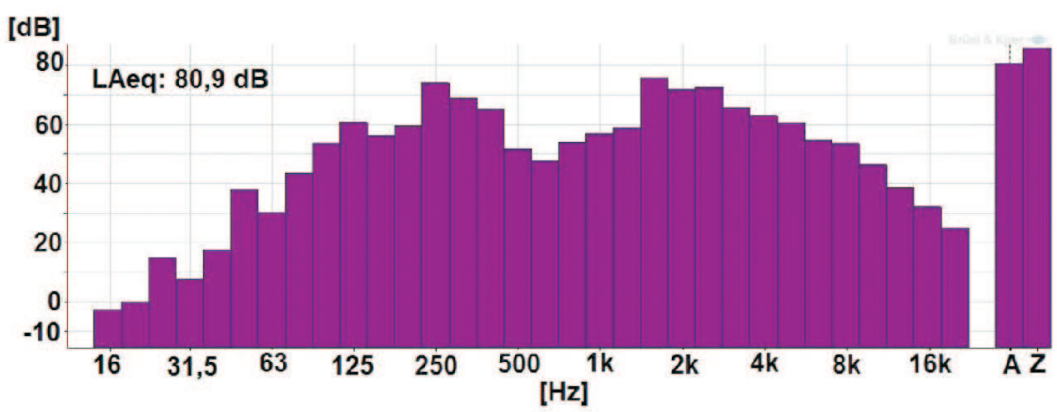

b)

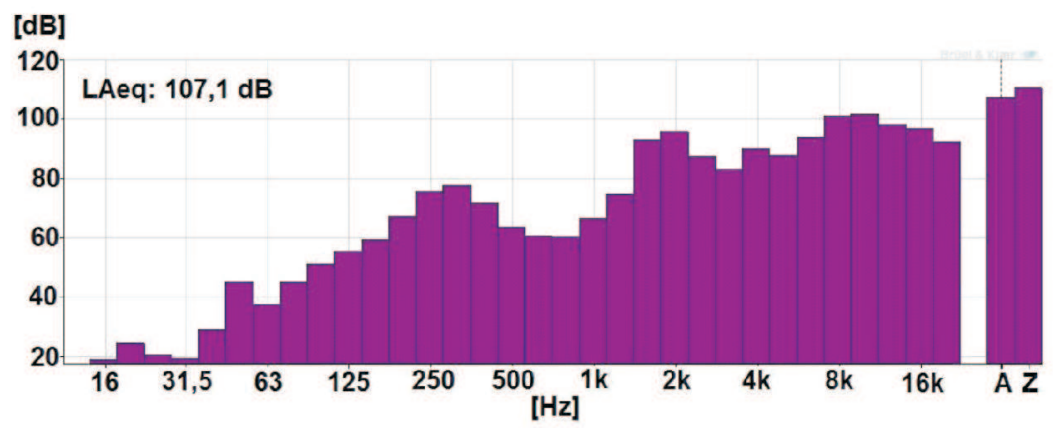

Fig. 7. a) Third spectrum of sound level for case without cavitation; b) Third spectrum of sound level for case with cavitation on diaphragm

ranges the spectra are very similar, and two dominant frequencies, i.e. about $250 \mathrm{~Hz}$ and $2 \mathrm{kHz}$, can be distinguished in them. On the other hand, in the flow with cavitation, there appears high-frequency noise with a frequency of $8-30 \mathrm{kHz}$.

In addition, studies aimed at reducing microfeeder vibration, and so lowering the level of the generated noise, were carried out. An internal gear pump (designed and built in-house) with unit delivery $\mathrm{q}_{p}=0,22 \mathrm{~cm}^{3} / \mathrm{rev}$. was used in the feeder. There were 15 teeth on each of the two gears and the gear pitch diameter was about $11.25 \mathrm{~mm}$. The micropump was driven by an electric motor with a speed of $1450 \mathrm{rpm}$. The pump has a three-plate structure (Fig. 8).

Front plate 1 is used for fixing the pump to the power unit. Middle plate 2 houses the gears. The back plate has a suction orifice and a pressure orifice, for connecting to the system. The plates are bolted together. The three-plate design is advantageous for constructional reasons (simple shape, convenient arrangement of the pump parts, easy attachment and fixing to the drive motor and to the system), assembly reasons (easy assembly and mutual 


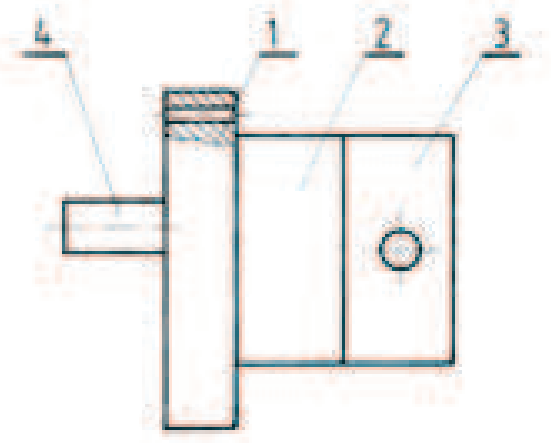

Fig. 8. Three-plate structure of gear pump: 1 - front (mounting) plate, 2 - middle (occular) plate, 3 - back (attachment) plate, 4 - shaft

connection of the components) and technological reasons (simple machining and convenient checking of the pump components).

The subject of the investigations was a hydraulic microfeeder for flows $<0.3 \mathrm{dm}^{3} / \mathrm{min}$, which during test starting was excessively noisy, and its working fluid tank lid was strongly vibrating. The characteristic of the feeder is shown in Fig. 9. The aim of the investigations was to identify the sources of the noise and the causes of the vibration and then to try to reduce the adverse phenomena through a proper upgrade.

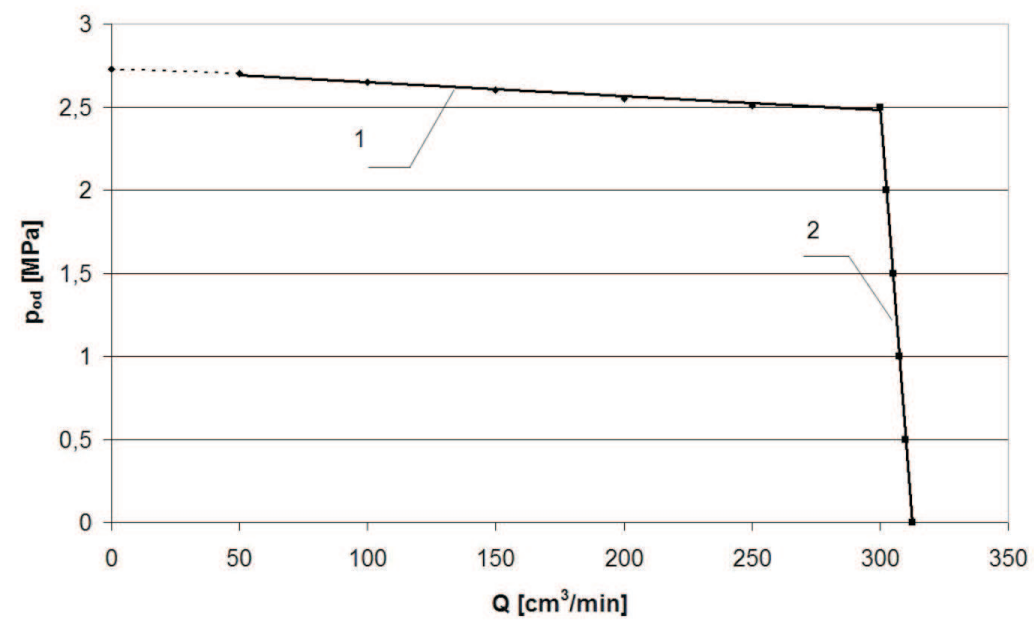

Fig. 9. Characteristic of hydraulic microfeeder: 1 - characteristics of safety valve, 2 - characteristic of micropump

When investigating microhydraulic components and systems one must ensure that the measuring system has no influence on the investigated object. 
For this reason, a touchless method using a laser vibrometer was employed to measure the vibration of the microfeeder's pressure relief valve. A block diagram of the touchless vibration measuring and recording system is shown in Fig. 10.

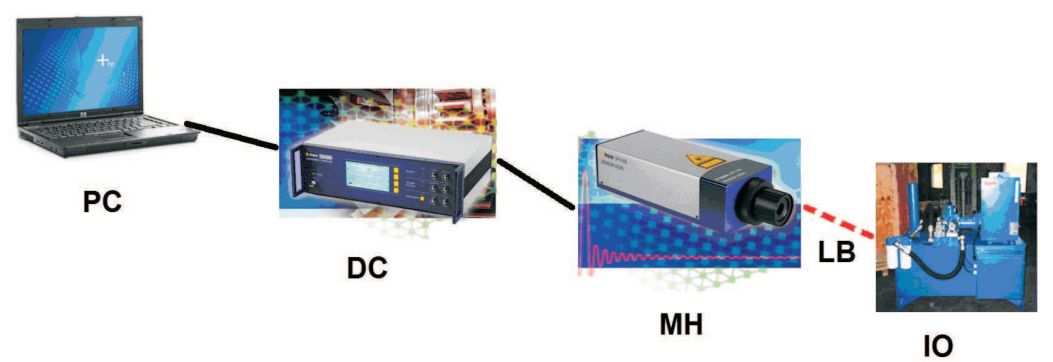

Fig. 10. Block diagram of vibration measuring and recording system with laser vibrometer: IO (investigated object) - in-house designed and built hydraulic feeder, LB - laser beam with $633 \mathrm{~nm}$ wavelength, MH - measuring head OFV-505 Polytec, DC - Polytec decoder, $\mathrm{PC}$ - computer with measuring data acquisition and analysis software

The results of the diagnostic measurements are shown as amplitude spectra of the signals, based on a narrow-band FFT analysis of displacements and a third analysis of sound pressure level $\mathrm{dB}$, and a pressure fluctuation spectrum - Figs 11, 12 and 13.

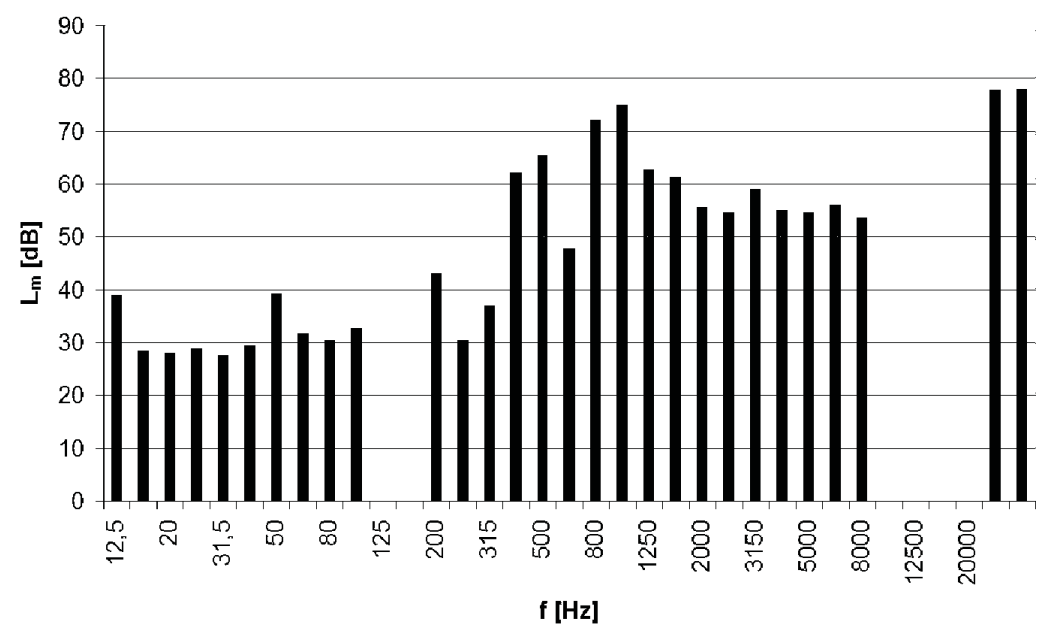

Fig. 11. Third noise spectrum of feeder before upgrade

An analysis of the diagnostic signal spectra shows that the highest relief microvalve displacement and noise level amplitudes occur at the same frequencies, i.e. 900-1000 Hz. Therefore one can conclude that, in the tested 


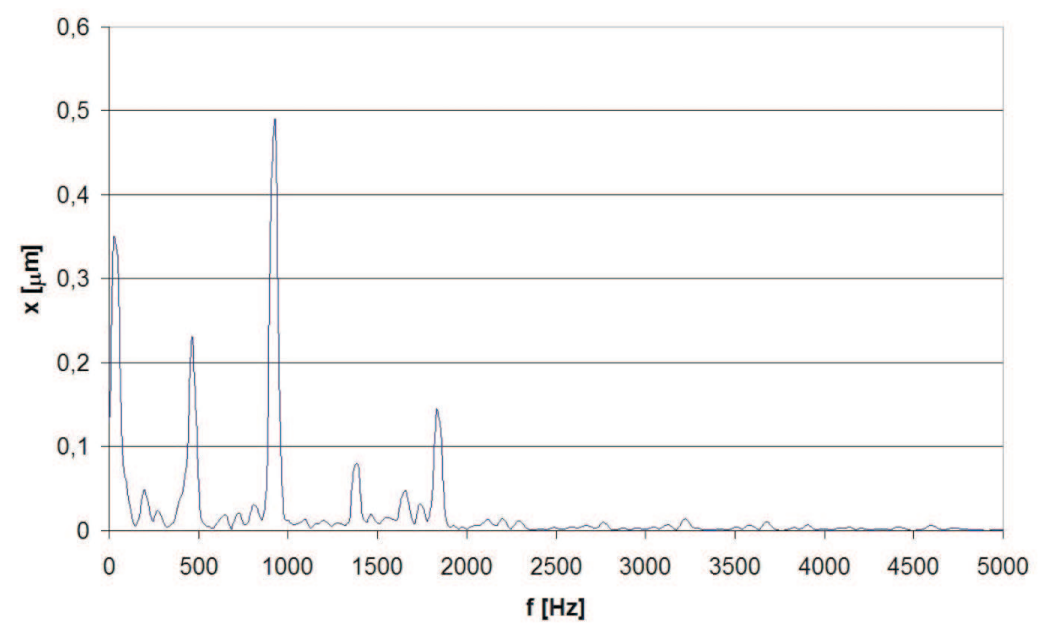

Fig. 12. Spectrum of relief valve (pressure adjusting screw) displacements before feeder upgrade

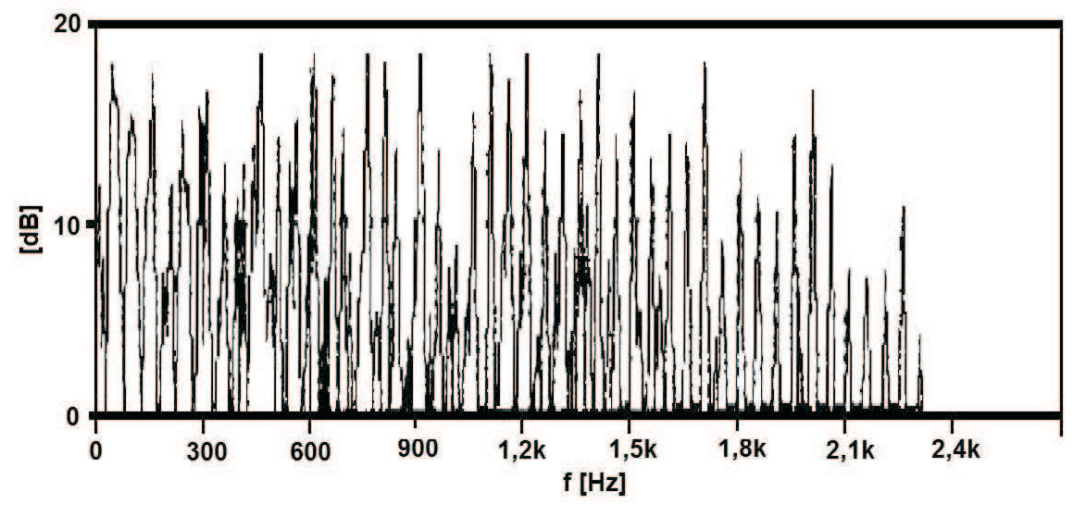

Fig. 13. Pressure fluctuation spectrum before feeder upgrade

parameter range, the operation of the microvalve is unstable, and the frequency of the valve head vibrations spreading throughout the feeder is close to the free vibration frequency. The microvalve is schematically shown in Fig. 14.

The following relation [7], [9] was used to estimate the valve's natural frequency:

$$
f_{0}=\frac{1}{2 \pi} \sqrt{\frac{W_{z} \cdot \mu \cdot \pi^{2} \cdot d^{2} \cdot \sin \alpha \cdot \sqrt{\frac{2 p_{1}}{\rho}}}{4 m}}
$$

where: $W_{z}$ - the valve amplification factor whose measure is the tangent of the slope of linearized static characteristic $p_{1}=\mathrm{f}\left(\mathrm{Q}_{z}\right)_{p 0}, \mu-$ the valve flow ratio (assumed according to [8]). 


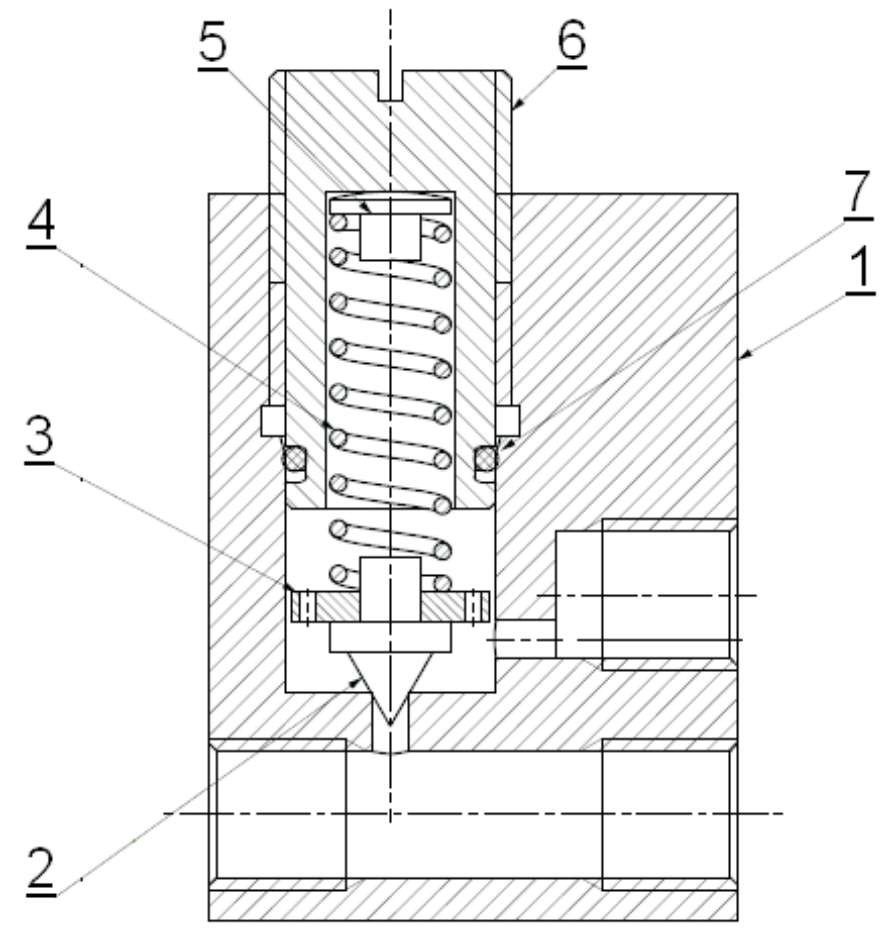

Fig. 14. Axial cross-section of relief valve: 1 - body, 2 - poppet, 3 - damping plate, 4 - spring, 5 - plate 6 - adjusting screw, 7 - seal

The above relation does not take into account the influence of the hydraulic system structure in which the valve is installed, and more precisely the influence of the compressibility of the working medium and the piping. In calculations of dynamic hydrostatic drive systems, compressibility (assuming concentrated parameters) is expressed as coefficient $K_{c}$ (called capacitance) being a ratio of volume $V_{u}$ occupied by the liquid in the system to equivalent volume elasticity modulus $B_{z}$ of the piping and the liquid, i.e.

$$
K_{c}=\frac{V_{u}}{B_{z}}
$$

If capacitance is assumed to be constant, the hydraulic circuit can be considered as an elastic mechanical system with reduced rigidity $c_{u}$ defined by this formula:

$$
c_{u}=\frac{S_{0}^{2} \cdot B_{z}}{V_{u}}
$$

where: $S_{0}=\frac{\pi \cdot d^{2}}{4}-$ the active surface of the valve head. 
Taking the compressibility effect into account through reduced rigidity $c_{u}$, which together with the rigidity of the valve's mechanical spring form a parallel arrangement, we can describe the frequency of the undamped free vibration of the single-stage relief valve by the following relation:

$$
f_{0}^{\prime}=\frac{1}{2 \pi} \sqrt{\frac{W_{z} \cdot \mu \cdot \pi^{2} \cdot d^{2} \cdot \sin \alpha \cdot \sqrt{\frac{2 p_{1}}{\rho}}}{4 m}+\frac{S_{0}^{2} \cdot B_{z}}{V_{u} \cdot m}}
$$

The model represented by equations (1) - (4) was described in [7], [8], [9] in detail.

When one takes into account the experimentally determined static characteristic of the valve (factor $W_{z}$ ), the geometric dimensions, the reduced mass of the vibrating system, and experimentally determined (using the method presented in [10]) coefficient $B_{z}$, the valve's resonant vibration calculated from relation (4) is $f_{0}^{\prime} \approx 900 \mathrm{~Hz}$. This attests to the fact that the cause of the excessive noise generated by the hydraulic feeder is the vibration of the valve head with the resonance frequency.

Stability can be effectively improved by increasing the capacitance of the system [11]. For this purpose, the metal pipe connecting the pump to the distributor was replaced with a flexible hose. As a result, the system's capacitance increased $\sim 120$ times, while the valve free vibration frequency decreased to $f_{0}^{\prime} \sim 320 \mathrm{~Hz}$.

The results of tests carried out after the upgrade are shown in Figs 15, 16 and 17.

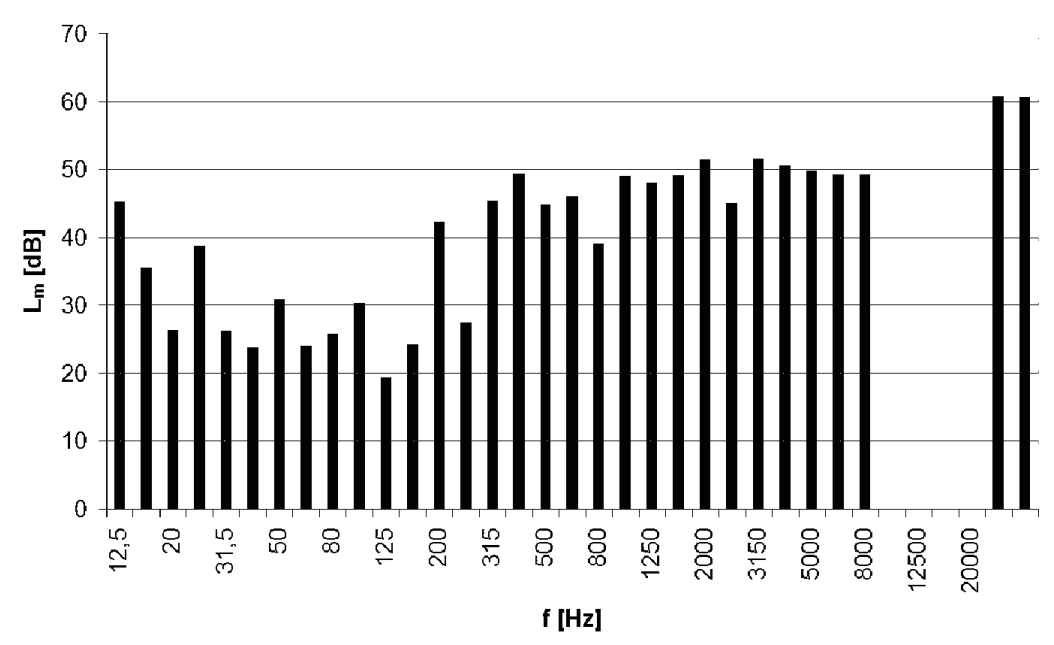

Fig. 15. Third noise spectrum after feeder upgrade 


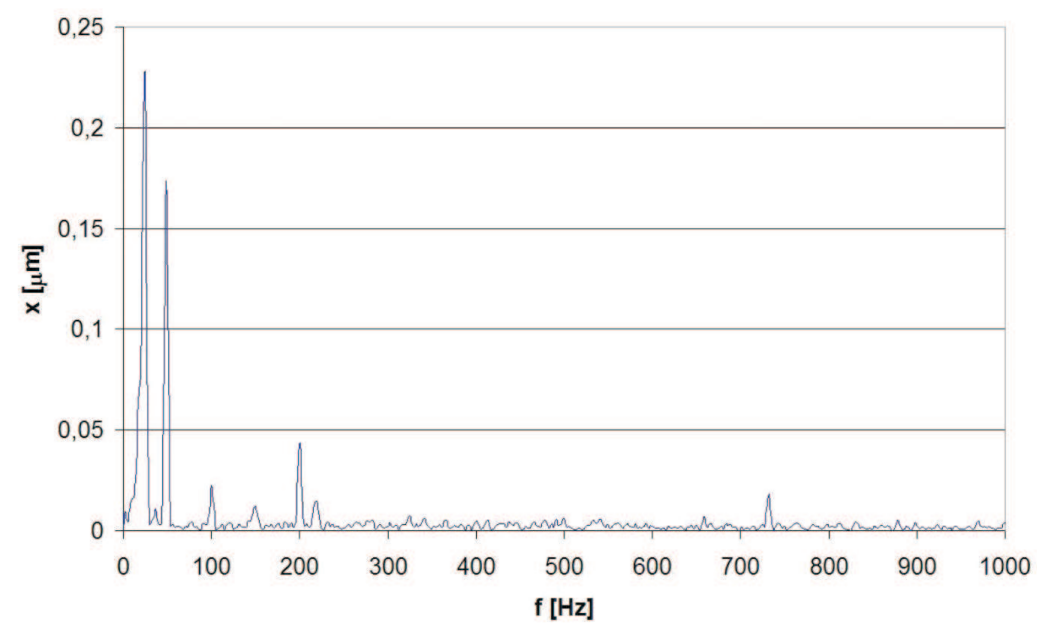

Fig. 16. Relief microvalve (pressure adjusting screw) displacement spectrum after feeder upgrade

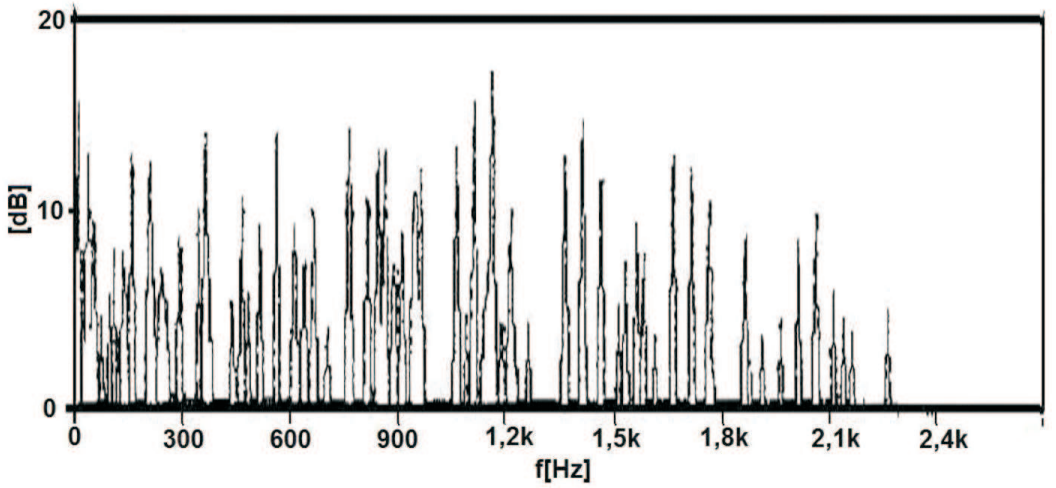

Fig. 17. Pressure fluctuation spectrum after feeder upgrade

As figure 16 shows, after the steel piping was replaced with flexible piping (whereby the hydraulic system's capacitance increased) the hydraulic feeder operated much quieter. Since the amplitude and frequency of pressure relief valve vibrations were reduced, sound level $\mathrm{L}_{A}$ decreased by as much as 15-17 dB (A) (Figs 11 and 15).

The effects of the replacement of the steel pipes $\left(\mathrm{d}_{p}=3 \mathrm{~mm}, 1_{p}=200\right.$ $\mathrm{mm})$ with flexible hoses $\left(\mathrm{d}_{p}=10 \mathrm{~mm}, 1_{p}=400 \mathrm{~mm}\right)$ on the sound level, the relief valve vibration acceleration level and the hydraulic feeder pressure pulsation amplitude are illustrated in Figs 15, 16 and 17. 


\section{Conclusion}

As mentioned above, microhydraulic systems and components increasingly find new applications and often replace conventional pneumatic or electromechanical systems. This does not mean, however, that the field of microhydraulics is devoid of problems. The sources of the problems need to be identified and eliminated through simulations and experiments. Since it is difficult to study hydrodynamic phenomena in actual hydraulic microcomponents, experimental investigations are sometimes conducted on a model component (larger than the actual one) and similarity criteria are applied. If possible, however, experiments should be carried out on a model identical with (or similar to) the actual component (e.g. a microvalve). Some problems relating to the design and operation of hydraulic microcomponents have been indicated and an exemplary method of reducing the vibration and noise of a hydraulic microfeeder has been proposed (Figs 15-17). The excessive noisiness was due to the unstable operation of the pressure relief valve. By increasing system capacitance, the acceleration of microvalve head vibrations and the amplitude of pressure fluctuations were reduced. The significant effect of working medium and piping compressibility on dynamic system parameters for hydrostatic drives with small and very small flows has been confirmed. It was stressed that, in the field of microhydraulics, special care should be taken to ensure that the measuring systems do not influence the investigated microobjects. In order for hydraulic microcomponents and microsystems to be competitive with conventional systems, one should carry out further research aimed at developing an algorithm for the design of microhydraulic systems, which would meet the requirements concerning operating reliability and accuracy, reduced noisiness and so on.

\section{Nomenclature:}

$\begin{array}{ll}\mathrm{Q} & - \text { flow intensity } \\ \mathrm{Q}_{z} & - \text { valve flow rate, } \\ \Delta \mathrm{p}_{\text {diaph }} & - \text { diaphragm pressure drop, } \\ \mathrm{LAeq} & - \text { equivalent sound level, } \\ \mathrm{L}_{A} & - \text { sound level, } \\ \mathrm{q}_{p} & - \text { unit delivery, } \\ \mathrm{v}_{\text {diaph }} & - \text { diaphragm flow velocity, } \\ W_{z} & - \text { the valve amplification factor, }\end{array}$


$\mu \quad-$ the valve flow ratio,

$\mathrm{d} \quad-$ the valve seat diameter

$\mathrm{d}_{p} \quad-$ pipe diameter,

$1_{p} \quad-$ pipe length,

$\alpha \quad-$ the angle between the head's side surface and its symmetry axis,

$\rho \quad-$ the density of the working medium,

$p_{1}-$ the working pressure,

$m$ - the reduced mass equal to the head mass increased by one third of the spring mass,

$V_{u}-$ volume,

$B_{z}-$ equivalent volume elasticity modulus,

$K_{c}$ - capacitance,

$c_{u}$ - reduced rigidity,

$S_{0} \quad-$ the active surface of the valve head,

$f_{0} \quad$ - valve's natural frequency,

$f_{0}^{\prime} \quad-\quad$ frequency of the undamped free vibration

Manuscript received by Editorial Board, May 19, 2010; final version, July 06, 2010.

\section{REFERENCES}

[1] Ławniczak A.: Low-speed hydraulic drives (in Polish). Poznań Polytechnic, Rozprawy No. 154, Poznań 1988.

[2] Byung-Phil M., Mi-Young S., Ho-Seung J., Chul-Ju K.: Fabrication of a No-Leakage MicroValve with a Free-Floating Structure for a Drug-Delivery System. Journal of the Korean Physical Society, 43, 5, November 2003, pp. 930-934.

[3] Dindorf R., Wołkow J.: Fluid microsystems. Microhydraulics (in Polish). All-Poland Conference CYLINDER'2000. Szczyrk, 27-29 September 2000, pp. 62-68.

[4] www.hydroleduc.com

[5] www.hoerbiger.com

[6] Palczak E., Gawryś E., Kudźma Z.: Investigation of flows and noisiness in microhydraulics (in Polish). Institute of Machines Design and Operation at Wrocław University of Technology, Sprawozdania series report no. 004/2000. Wrocław 2000.

[7] Kudźma Z:: Assessment of dynamic properties of single-stage pressure relief valves, based on static characteristics (in Polish). Sterowanie i Napęd Hydrauliczny no. 6, 1989.

[8] Kollek W., Kudźma Z.: Effect of lift valve head and seat geometry on flow ratio (in Polish). Sterowanie i Napęd Hydrauliczny no. 6, 1983.

[9] Kudźma Z.: An influence of poppet-seat shape on static and dynamic properties of maximum valves. Ph.D. Wrocław University of Technology, Thesis. Institute of Machines Design and Operation, Wrocław 1980. 
[10] Fiebig W., Kudźma Z.: Starting of hydrostatic converter with relief valve participation (in Polish). Sterowanie i Napęd Hydrauliczny no. 6, 1990.

[11] Serwach A.: Analysis of overflow valve stability (in Polish). Prace Instytutu Lotnictwa no. 38, 1969.

Problemy akustyczne elementów i układów mikrohydraulicznych

\section{Streszczenie}

W pracy przedstawiono wybrane przykłady zastosowań zminiaturyzowanych elementów hydraulicznych proponowanych przez wyspecjalizowanych producentów oraz podano wyniki niektórych prac własnych nad zjawiskami związanymi z mikroprzepływami. W artykule prezentuje się m.in. wyniki pomiarów drgań zaworu przelewowego mikrozasilacza hydraulicznego wykonane za pomocą wibrometru laserowego - metodą bezdotykową. Wykorzystanie do pomiarów w obszarze mikrohydrauliki wibrometru laserowego podyktowane było koniecznością wyeliminowania wpływu przyrządów pomiarowych na badany obiekt. Szczególną uwagę skupiono na problemach akustycznych: źródłach hałasu i metodach jego redukcji. 